\title{
SPECIFICS OF RUSSIAN SPEAKERS' COMMUNICATIVE BEHAVIOR IN INTERPERSONAL COMMUNICATION (BASED ON THE FINDINGS OF EXPERIMENTAL RESEARCH)
}

\author{
Kseniya S. Kardanova-Biryukova \\ Moscow City University, Moscow, Russia
}

\begin{abstract}
The paper focuses on the findings of the experiment, which involved Russian native speakers aged between 17 and 24 (both males and females). The objective of the experiment was to derive an algorithm of communicative behavior of interpersonal communication's participants and to determine the sequence of verbal / non-verbal actions of a communicant in various situations. The experiment is based upon the theoretical foundations of the autopoiesis theory by H. Maturana and F. Varela, which views communication as a natural response of the living system to a dissonance occurring between it and its niche. On the basis of this theoretical premise we can model communicative behavior of a person as a non-linear sequence of verbal / non-verbal actions. Their features and the very number of such actions hinge on the relevance of dissonance-triggering factors for the communicant.

The statistical analysis and the interpretation outlined in the paper help unveil whether such communicative behavior is stereotypical or is determined by the communicant's personality. To uncover group-related characteristics of communicative behavior with a focus on gender and society-determined characteristics, the cluster of subjects has been further subdivided into smaller and more unified clusters. The trends identified have been scrutinized, interpreted and supported with relevant examples of the subjects' responses.

Key words: interpersonal communication, communicative behavior, experiment, autopoiesis theory, verbal action, non-verbal action, communication situation.

Citation. Kardanova-Biryukova K.S. Specifics of Russian Speakers' Communicative Behavior in Interpersonal Communication (Based on the Findings of Experimental Research). Vestnik Volgogradskogo gosudarstvennogo universiteta. Seriya 2, Yazykoznanie [Science Journal of Volgograd State University. Linguistics], 2018, vol. 17, no. 1, pp. 85-97. (in Russian). DOI: https://doi.org/10.15688/jvolsu2.2018.1.9
\end{abstract}

\section{ОСОБЕННОСТИ КОММУНИКАТИВНОГО ПОВЕДЕНИЯ НОСИТЕЛЕЙ РУССКОГО ЯЗЫКА В МЕЖЛИЧНОСТНОМ ОБЩЕНИИ (ЭКСПЕРИМЕНТАЛЬНОЕ ИССЛЕДОВАНИЕ)}

\author{
Ксения Суфьяновна Карданова-Бирюкова \\ Московский городской педагогический университет, г. Москва, Россия
}

Аннотация. В статье представлены результаты эксперимента, проведенного с носителями русского
языка. Цель эксперимента заключалась в том, чтобы алгоритмизировать коммуникативное поведение учас-
тников межличностного общения, выстроив последовательность речевых / неречевых действий коммуни-
канта в различных коммуникативных ситуациях. Теоретическую основу экспериментального исследования
составляет теория аутопоэза, в которой коммуникация - один из видов взаимодействия между членами
социума - понимается как естественная реакция живой системы на дисбаланс, возникший между нею и ее 


\section{РАЗВИТИЕ И ФУНКЦИОНИРОВАНИЕ РУССКОГО ЯЗЫКА}

средой. Опора на этот постулат позволяет моделировать коммуникативное поведение человека как нелинейную последовательность речевых / неречевых действий, характер и количество которых определяются релевантностью факторов, спровоцировавших дисбаланс, для коммуниканта. Представленные в статье статистическая обработка данных и интерпретация полученных результатов позволяют оценить, является ли коммуникативное поведение в предъявленных в эксперименте ситуациях социально маркированным и стереотипным или детерминируется индивидуальными характеристиками коммуниканта. Для выявления гендерно и социально маркированных особенностей коммуникативного поведения экспериментальная выборка была разбита на несколько подгрупп. Обнаруженные тренды были детально проанализированы, проинтерпретированы и подкреплены соответствующими примерами.

Ключевые слова: межличностная коммуникация, коммуникативное поведение, эксперимент, теория аутопоэза, речевое действие, неречевое действие, коммуникативная ситуация.

Цитирование. Карданова-Бирюкова К.С. Особенности коммуникативного поведения носителей русского языка в межличностном общении (экспериментальное исследование) // Вестник Волгоградского государственного университета. Серия 2, Языкознание. - 2018. - Т. 17, № 1. - С. 85-97. - DOI: https://doi.org/ 10.15688/jvolsu2.2018.1.9

\section{Введение}

Одна из центральных проблем изучения коммуникации состоит в выявлении универсальных закономерностей коммуникативного поведения человека, которые можно экстраполировать на весь языковой коллектив. Исследования, посвященные этой проблеме, можно разделить на три группы. Первая группа объединяет работы, в которых изучается то, как происходит передача информации от адресанта к адресату в пределах одного речевого действия (К. Шеннон, У. Уивер, Н. Винер, Ч. Осгуд, М. Дефлюэр и др.). При этом говорящий и слушающий рассматриваются как конечные точки коммуникативного взаимодействия, между которыми располагаются технические приспособления, опосредующие коммуникацию (кодирующие и декодирующие ее), шумы и прочие элементы акта коммуникации. Опираясь на эту схему, исследователь может, например, высчитывать (часто используя математические методы) то, какое количество информации было утеряно в процессе передачи. При этом учитывается влияние шумов (см., например, [Шеннон, 1963] и др.), различия структуры и содержания сознания говорящего и слушающего и несоответствия их коммуникативного опыта.

Вторая группа включает исследования, характеризующие коммуникацию как комплексный нелинейный процесс, результат которого состоит в поддержании и / или развитии социальной организации (К.-О. Апель, Ю. Хабермас и др.). Такие исследования часто носят философский характер и не предполагают описания частных речевых действий.

Третью группу составляют исследования уже реализованного акта коммуникации. В них предложены классификации речевых актов и коммуникативных стратегий, используемых носителями языка (Дж. Серль, Дж. Остин, О.С. Иссерс, Ю.К. Пирогова и др.). Эти классификации позволяют выявить наиболее частотные стратегии, однако они не приближают нас к ответу на вопрос о том, какие факторы способствуют тому, что человек совершает те или иные речевые действия, выбирает те или иные коммуникативные стратегии в тех или иных ситуациях общения.

Однако в вышеназванных исследованиях всех трех групп не учитывается процессуальность коммуникации и не решается задача алгоритмизации последовательности речевых действий участников межличностного общения, предполагающая рассмотрение коммуникации как комплексного процесса, развитие которого определяется и внешними (условия и формат общения), и внутренними (социокогнитивные характеристики коммуникантов) факторами.

Как представляется, решение этой задачи возможно при трактовке коммуникации как гибкого, нелинейного динамического взаимодействия. Теоретическую основу этого подхода формирует теория аутопоэза, в которой коммуникация понимается как процесс постоянной адаптации живой системы (в частности, человека) к постоянно изменяющейся среде [Матурана, Варела, 2001; Maturana, 1978; Maturana, Varela, 1980 и др.]. Поскольку 
и живая система, и среда обладают гибкостью и адаптивностью, равновесие, при котором живая система пребывает в состоянии покоя и неактивна, является вре́менным (эмерджентным). В моменты, когда равновесие нарушено, система начинает совершать действия, направленные на восстановление баланса со средой, что, в свою очередь, приводит к ответной адаптации со стороны среды. Следовательно, коммуникация как один из видов взаимодействия между членами социума - естественная реакция живой системы на дисбаланс, возникший между нею и ее средой. В результате и в живой системе, и в среде происходит определенная структурная перестройка, приводящая к их эволюции.

Для того чтобы ответить на исследовательский вопрос «Какие факторы определяют последовательность речевых действий коммуниканта? Являются ли они универсальными или индивидуальными?», был проведен эксперимент с носителями русского языка. Цель эксперимента состояла в том, чтобы выстроить последовательность речевых / неречевых действий коммуниканта в ряде ситуаций бытового межличностного общения.

\section{Описание эксперимента}

Согласно проверяемой экспериментальной гипотезе, коммуникант идентифицирует соииальный дисбаланс исходя из собственного актуального состояния, которым задается алгоритм коммуникации. Предполагаем, что различие актуальных состояний ряда коммуникантов будет определять различные сценарии их коммуникативного поведения.

Для проверки гипотезы было разработано экспериментальное задание, в котором испытуемым предложен ряд коммуникативных ситуаций, предполагающих ответное действие, в том числе речевое (для взаимной верификации полученных данных). В описании каждой ситуации был назван некий «раздражитель», который может вывести участника социального взаимодействия из состояния равновесия:

Ситуация 1. К Вам обратился с вопросом мужчина на улице. Вы не расслышали вопрос. Ваши действия.
Ситуация 2. В метро Вас буквально внесли в переполненный вагон. Вы кого-то случайно задели рукой. Вам сделали замечание. Ваши действия.

Ситуация 3. Вы общаетесь со знакомым/ой на остановке автобуса. Человек, также ожидающий автобус, сльшит, о чем Bы говорите, и начинает участвовать в разговоре. Ваши действия.

Ситуация 4. Bы отвечаете на комментарий к Вашей фотографии в сочиальной сети. В комментарии содержится критика. Ваши действия.

При выполнении экспериментального задания испытуемым было предложено описать последовательность речевых / неречевых действий в предъявленных им экспериментальных ситуациях.

Вместе с тем предполагалось, что, в соответствии со свойствами коммуникантов, такой «раздражитель» мог оказаться не основным, а испытуемыми могли быть выявлены иные раздражающие факторы. Анализ предложенных испытуемым сценариев поведения позволяет определить, становится ли заложенный в предъявленной ситуации раздражитель основным для выстраивания сценария дальнейшего поведения. Более того, статистическая обработка ответов испытуемых дает возможность установить степень унификации коммуникативного поведения представителей разных групп, обладающих теми или иными гендерными, возрастными и социо-когнитивными характеристиками.

Экспериментальную выборку составляют 144 испытуемых в возрасте от 17 до 24 лет, разделенные на две экспериментальные группы по гендерному признаку (85 женщин vs. 59 мужчин). Выделение двух гендерных групп обусловлено необходимостью верифицировать выдвинутое на этапе планирования эксперимента предположение о том, что наиболее выраженные особенности адаптивного поведения наблюдаются на стыке групп, обладающих разными социо-когнитивными характеристиками (гендерными, возрастными, профессиональными, социальными и пр.).

\section{Результаты эксп еримента}

Статистическая обработка ответов испытуемых происходила в несколько этапов: на 


\section{РАЗВИТИЕ И ФУНКЦИОНИРОВАНИЕ РУССКОГО ЯЗЫКА}

первом этапе ответы были распределены в группы в зависимости от того, какое количество ответных речевых / неречевых действий прогнозирует потенциальный участник коммуникации в заданной экспериментальной ситуации, на втором этапе были подсчитаны те ответы, в которых предлагались нелинейные сценарии коммуникативного поведения, далее были выявлены частные особенности выстраиваемого участниками эксперимента коммуникативного поведения, которые определялись конкретной экспериментальной ситуацией. На основании выявленных трендов была проведена интерпретация результатов эксперимента и установлены межгрупповые и внутригрупповые особенности коммуникативного поведения участников межличностного общения.

Экспериментальная группа I (85 женщин в возрасте от 17 до 24 лет).

Анализ ответов испытуемых этой группы показал, что количество ответных речевых / неречевых действий, прогнозируемых участниками эксперимента, определяется рядом факторов.

1. Типичность коммуникативной ситуации (чем более шаблонной является коммуникативная ситуация, тем меньше ответных речевых / неречевых действий прогнозируют участники эксперимента). Так, наиболее шаблонной является ситуация, описывающая замечание в вагоне поезда в метро, поэтому количество прогнозируемых ответных речевых / неречевых действий в этой ситуации минимально: одно либо два ответных действия, три действия отмечены только в одном ответе, а четыре действия не выстраиваются в принципе (табл. 1). Ср.: одно ответное речевое / неречевое действие (Вежливо извинюсь ${ }^{1}$ (сохранена авторская орфография и пунктуация, индекс обозначает порядковый номер речевого / неречевого действия, называемого испытуемым);
Закачу глаза ; Пожелать хорошего дня! ${ }^{1}$ ); два ответных речевых / неречевых действия (Извинюсь ${ }^{1}$ и буду ульбаться ${ }^{2}$ Извинюсь ${ }^{1} u$ скажу ${ }^{2}$, что сделала это не специально); три ответных речевых / неречевых действия ( $Я$ смушусь $^{l}$, тихо извинюсь ${ }^{2}$ и буду еще долго из-за этого переживать ${ }^{3}$ ).

2. Характер взаимодействия (чем более дистанционным является взаимодействие, тем чаще испытуемые не воспринимают раздражитель как часть своей среды). Так, в экспериментальной ситуации № 4 моделируется взаимодействие между участниками интернет-общения, в котором коммуниканты обладают определенной свободой выбора, с кем и как долго общаться. Предоставляемая интернет-средой свобода коммуникативного взаимодействия позволяет участникам интернет-коммуникации выстраивать свою среду в соответствии с собственными желаниями и потребностями, как включая в нее дополнительные средовые факторы или исключая (нивелируя) их. Анализ экспериментальных данных показал, что испытуемые прогнозируют минимальное количество ответных речевых / неречевых действий: одно либо два действия (см. табл. 2). Это также подтверждается наличием сравнительно большого количества отказов $(9 \%)$. Дополнительным аргументом в поддержку этой точки зрения являются ответы, в которых участники эксперимента специально оговаривают, что они готовы отвечать на критические комментарии только знакомых людей: Если критика чужсого человека, то не стану обращать внимание и удалю комментарий. Если знакомый, то напишу ему в л.с. и поговорю с ним; Оиеню, кем является комментатор, знаюо ли я его, и насколько близко мы общаемся. Если это незнакомый человек, то не буду отвечать на комментарий, если же комментарий друга или знакомого, то, возможно, прислушаюсь к критике.

Количество речевых / неречевых действий, требуемых для восстановления равновесия со средой (экспериментальная ситуация № 2)

\begin{tabular}{|l|c|}
\hline \multicolumn{1}{|c|}{ Количество действий } & Количество ответов испытуемых \\
\hline Одно речевое / неречевое действие & $59(69,4 \%)$ \\
\hline Два речевых / неречевых действия & $25(29,4 \%)$ \\
\hline Три речевых / неречевых действия & $1(1,2 \%)$ \\
\hline Четыре речевых / неречевых действия & - \\
\hline
\end{tabular}


Количество речевых / неречевых действий, требуемых для восстановления равновесия со средой (экспериментальная ситуация № 4)

\begin{tabular}{|l|c|}
\hline \multicolumn{1}{|c|}{ Количество действий } & Количество ответов испытуемых \\
\hline Одно речевое / неречевое действие & $67(79 \%)$ \\
\hline Два речевых / неречевых действия & $10(12 \%)$ \\
\hline Три речевых / неречевых действия & - \\
\hline Четыре речевых / неречевых действия & - \\
\hline Отказ & $8(9 \%)$ \\
\hline
\end{tabular}

В тех ситуациях, когда коммуникативное взаимодействие инициировано человеком, который непосредственно обращается к субъекту коммуникативного взаимодействия (как в экспериментальных ситуациях № 1 и № 3), равновесие между живой системой и средой, как правило, нарушается. В связи с этим субъект коммуникативного взаимодействия обязан учитывать данный средовый фактор и совершать ответные речевые / неречевые действия для восстановления баланса со средой. При этом количество прогнозируемых ответных действий будет бо́льшим, чем в экспериментальных ситуациях 2 и 4 (табл. 3,4 ). Ср.: одно ответное речевое / неречевое действие (Переспрошу вопрос ${ }^{1}$; Игнорирую его ${ }^{l}$; Замолчу $\left.{ }^{l}\right)$; два ответных речевых / неречевых действия (Извинюсь ${ }^{1}$ за то, что не расслышала вопрос, и переспрошу ${ }^{2}$; Спокойно выслушаю ${ }^{1}$ то, о чем он говорит, если это будет что-то нормально и подходящее, то, что возможно, продолжу беседу ${ }^{2}$ с его участием; Переспрошу ${ }^{l}$ и попытаюсь помочь ${ }^{2}$ ); три ответных речевых / неречевых действия (Я остановлюсь ${ }^{1}$ и вежливо переспрошу ${ }^{2}$. Если я знаю ответ на вопрос, я постараюсь помочь ${ }^{3}$ этому человеку; Сначала оценю ${ }^{l}$ адекватность собеседника, не представляет ли он опасности, затем попрошу ${ }^{2}$ повторить его вопрос, u постараюсь оказать нужную помощь ${ }^{3}$ ); четыре ответных речевых / неречевых действия (Посмотрю ${ }^{1}$ на него с диким удивлением, переглянусь ${ }^{2}$ с другом, посмеюсь ${ }^{3}$, отойду ${ }^{4}$ вместе с другом; Выташу наушники, ульбнусь ${ }^{2}$, извинюсь ${ }^{3}$, попрошу повторить $\left.{ }^{4}\right)$.

Следует особо отметить случаи, когда участники эксперимента называют одно или два ответных речевых / неречевых действия,

Количество речевых / неречевых действий, требуемых для восстановления равновесия со средой (экспериментальная ситуация № 1)

\begin{tabular}{|l|c|}
\hline \multicolumn{1}{|c|}{ Количество действий } & Количество ответов испытуемых \\
\hline Одно речевое / неречевое действие & $32(38 \%)$ \\
\hline Два речевых / неречевых действия & $42(49 \%)$ \\
\hline Три речевых / неречевых действия & $10(19 \%)$ \\
\hline Четыре речевых / неречевых действия & $1(1 \%)$ \\
\hline
\end{tabular}

Количество речевых / неречевых действий, требуемых для восстановления равновесия со средой (экспериментальная ситуация № 3)

\begin{tabular}{|l|c|}
\hline \multicolumn{1}{|c|}{ Количество действий } & Количество ответов испытуемых \\
\hline Одно речевое / неречевое действие & $49(58 \%)$ \\
\hline Два речевых / неречевых действия & $31(36 \%)$ \\
\hline Три речевых / неречевых действия & $3(4 \%)$ \\
\hline Четыре речевых / неречевых действия & $1(1 \%)$ \\
\hline Отказ & $1(1 \%)$ \\
\hline
\end{tabular}

Таблииа 4 


\section{РАЗВИТИЕ И ФУНКЦИОНИРОВАНИЕ РУССКОГО ЯЗЫКА}

поскольку это показывает, что коммуникант моделирует коммуникативную ситуацию сравнительно поверхностно, с учетом только базовых элементов. В число таких элементов входят очевидные, легко прогнозируемые речевые / неречевые действия. При этом количество таких элементов минимально: Переспрошу; Попросить повторить вопрос; Переспрошу, что он хотел (экспериментальная ситуация № 1); Извиниться; Попрошу прощения; Подумаю, что не мне (экспериментальная ситуация № 2); Послушать нового собеседника; Выслушать человека; Продолжу разговор; Попрошу не влезать в чужие дела (экспериментальная ситуация № 3); Удалить комментарий; Приму к сведению критику в мой адрес; Поблагодарить за критику; Поставлю грустный смайлик (экспериментальная ситуация № 4).

Наиболее показательны те случаи, когда испытуемые в принципе невоспринимают заложенный в экспериментальной ситуации раздражитель как создающий дисбаланс между живой системой (самим коммуникантом) и его средой. Вероятно, у такого коммуниканта раздражитель не входит в выстраиваемую им нишу.

Так, при предъявлении испытуемым экспериментальной ситуации № 1 были получены следующие ответы, предполагающие, что раздражитель не был включен в среду: Не обрашу внимание; Если хорошее настроение переспрошу. Если плохое - сделаю вид, что не заметила, пойду дальше; Прошла бы дальше. Если хорошее настроение, сниму наушники и помогу; Это зависит от моего настроения. Я могу переспросить, а могу сделать вид, что не усльшала его, и пройти мимо; Остановлюсь и попрошу повторить вопрос. Если данная ситуация происходит на безлюдной улице, то пойду дальше; Вежливо переспрошу: - промолчу, переспрошу, - отвечу; Сделаю вид, что не поняла вопроса, и пойду дальше; Переспрошу (если на улице темно, то убегу) и др. Следует обратить внимание на то, что часто такое ответное действие рассматривается как составляющая нелинейного сценария.

При предъявлении участникам эксперимента экспериментальной ситуации № 2 было получено сравнительно много ответов, в которых, в сущности, содержится отказ от со- вершения ответного речевого / неречевого действия: Прошгнорирую или извинюсь (зависит от ситуации); Промолчу; В зависимости от настроения. Могу извиниться, могу промолчать, могу ответить в грубой форме; Если би я задела рукой, то сразу бы извинилась. А если бы мне сделали после этого еще замечание, сделала бы вид, что не услышала, но более вероятно просто промолчала; Либо проигнорирую, либо извинюсь; Проигнорирую, не вижу смысла вступать в перепалки в таких условиях; Промолчу и др.

Наименьшее количество ответов, содержащих отказ от совершения ответного речевого / неречевого действия, было получено при предъявлении экспериментальной ситуации № 3, что, вероятно, связано с тем, что в данной ситуации функцию раздражителя выполняет непосредственно человек в ситуации социальной коммуникации. Непосредственное обращение к коммуниканту требует совершения ответного речевого действия, которое, в свою очередь, может быть как предполагающим дальнейшую коммуникацию, так и препятствующим дальнейшему взаимодействию. Тем не менее раздражитель как таковой в абсолютном большинстве случаев становится частью среды коммуниканта и предполагает совершение какого-либо ответного речевого / неречевого действия. В связи с этим отказ от взаимодействия содержался только в единичных ответах: Промолчать; Игнорировать; Промолчу, никак не отреагирую и др. При этом такие сценарии, как правило, являются линейными.

В экспериментальной ситуации № 4 количество ответов, в которых содержится отказ от совершения ответного речевого / неречевого действия, является наибольшим в силу специфики предъявленной коммуникативной ситуации (общение в интернет-среде). Как отмечалось выше, коммуникант считает возможным не рассматривать раздражитель как часть своей среды в тех случаях, когда коммуникативное взаимодействие является дистантным и обезличенным. С этим, как представляется, связано и значительное количество отказов (9\%), и большое число ответов, в которых содержится отказ от совершения ответного действия: Равнодушие; Я ее про- 
игнорирую. Критика чего-либо в социальных сетях - абсолютно несерьезно; Прочгнорирую; Если критика обоснована - «спасибо». Если нет - даже комментировать не стану; Я, как правило, не отвечаю на подобные сообщения; и др. Подобные действия (отказы от действий) часто представлены как вариант развития нелинейного сценария, при этом критерием выбора того или иного коммуникативного поведения является оценка степени «адекватности» критики, то есть субъективное восприятие критики как обоснованной или необоснованной.

Экспериментальная группа II (59 мужчин в возрасте от 17 до 24 лет).

В экспериментальной группе II количество прогнозируемых ответных речевых / неречевых действий зависит от ряда факторов.

1. Стереотипность коммуникативного поведения. Анализ экспериментальных данных показал, что статистически значимое количество развернутых ответных коммуникативных сценариев (в которые вошло больше двух речевых / неречевых действий) было получено только при предъявлении испытуемым экспериментальной ситуации № 1: Обратить внимание на мужчину ${ }^{l}$, поздороваться ${ }^{2}$ и попросить повторить его вопрос $^{3}$. В любом случае попытаться помочь ему ${ }^{4}$, даже если не знаешь точного ответа на вопрос; Остановлюсь ${ }^{1}$, переспрошу вопрос ${ }^{2}$. В случае возможности помочь помогу ${ }^{3}$, если нет - пойду дальше ${ }^{3}$, Извиняясь ${ }^{1}$ nереспрошу ${ }^{2}$, постараюсь как можно подробнее дать ответ ${ }^{3}$, если не смогу ответить, «горячо» извинюсь ${ }^{3}$; Остановиться ${ }^{1}$, поздороваться ${ }^{2}$, вежливо переспросить вопрос ${ }^{3}$ и попытаться помочь ${ }^{4}$; Попрошу повторить вопрос ${ }^{1}$, внимательно выслушаю ${ }^{2}$ и постараюсь ответить насколько это возможно ${ }^{3}$. Это связано с характером моделируемого социального взаимодействия: обратиться к прохожему за помощью рассматривается как норма социального взаимодействия (неагрессивное проникновение раздражителя в среду живой системы), что требует соответствующего ответного речевого / неречевого поведения. Именно поэтому участники эксперимента моделируют сценарии вежливого коммуникативного поведения, в которые входит достаточное количество шагов для достижения социального равновесия (табл. 5).

В ответах, полученных при предъявлении остальных экспериментальных ситуаций, развернутых сценариев коммуникативного поведения было существенно меньше (в некоторых случаях они отсутствовали) (см. табл. 6-8).

2. Вежливость как социальная норма. Анализ экспериментальных данных показал, что для мужчин в возрасте от 17 до 24 лет важно моделировать сценарии вежливого коммуникативного поведения. Испытуемые специально оговаривают, что в заданной экспериментальной ситуации их ответные действия будут вежливыми: Вежливо переспросить, после чего постараться ответить на вопрос; Вежнливо переспрошу мужчину, если человек выглядит достаточно доброжелательно; Вежсливо попросить повторить, извинившись за невнимательность; Переспросить в вежливой форме и помочь (экспериментальная ситуация № 1); Вежжливо извинюсь; Вежливо, хладнокровно извинюсь (экспериментальная ситуация № 2); Ответить вежливо, но достаточно равнодушно, так, чтобы ожидаюший понял, что его вмешательство нежелательно; Отойти, в вежливой форме показать человеку, что он лезет не в свое дело; Вежливо покажу человеку, что он является лишним в разговоре; Вежлииво скажу, что мы не интересу-

Таблица 5

Количество речевых / неречевых действий, требуемых для восстановления равновесия со средой (экспериментальная ситуация № 1)

\begin{tabular}{|l|c|}
\hline \multicolumn{1}{|c|}{ Количество действий } & Количество ответов испытуемых \\
\hline Одно речевое / неречевое действие & $29(49,2 \%)$ \\
\hline Два речевых / неречевых действия & $19(32,2 \%)$ \\
\hline Три речевых / неречевых действия & $9(15,2 \%)$ \\
\hline Четыре речевых / неречевых действия & $2(3,4 \%)$ \\
\hline
\end{tabular}


Количество речевых / неречевых действий, требуемых для восстановления равновесия со средой (экспериментальная ситуация № 2)

\begin{tabular}{|l|c|}
\hline \multicolumn{1}{|c|}{ Количество действий } & Количество ответов испытуемых \\
\hline Одно речевое / неречевое действие & $45(76,3 \%)$ \\
\hline Два речевых / неречевых действия & $12(20,3 \%)$ \\
\hline Три речевых / неречевых действия & $1(1,7 \%)$ \\
\hline Четыре речевых / неречевых действия & - \\
\hline Отказ & $1(1,7 \%)$ \\
\hline
\end{tabular}

Количество речевых / неречевых действий, требуемых для восстановления равновесия со средой (экспериментальная ситуация № 3)

\begin{tabular}{|l|c|}
\hline \multicolumn{1}{|c|}{ Количество действий } & Количество ответов испытуемых \\
\hline Одно речевое / неречевое действие & $43(72,9 \%)$ \\
\hline Два речевых / неречевых действия & $12(20,3 \%)$ \\
\hline Три речевых / неречевых действия & $2(3,4 \%)$ \\
\hline Четыре речевых / неречевых действия & $1(1,7 \%)$ \\
\hline Отказ & $1(1,7 \%)$ \\
\hline
\end{tabular}

Количество речевых / неречевых действий, требуемых для восстановления равновесия со средой (экспериментальная ситуация № 4)

\begin{tabular}{|l|c|}
\hline \multicolumn{1}{|c|}{ Количество действий } & Количество ответов испытуемых \\
\hline Одно речевое / неречевое действие & $43(72,9 \%)$ \\
\hline Два речевых / неречевых действия & $7(11,9 \%)$ \\
\hline Три речевых / неречевых действия & $3(5,1 \%)$ \\
\hline Четыре речевых / неречевых действия & - \\
\hline Отказ & $6(10,2 \%)$ \\
\hline
\end{tabular}

емся в этом мнении; Если разговор идет на личные темы, то показать, что его речи неуместны в вежлливой форме, или поставить его в тупик ответным вопросом. Если разговор на общие темы, выслушать его мнение и, возможно, обсудить (экспериментальная ситуация № 3). Только при предъявлении испытуемым экспериментальной ситуации № 4 подобные сценарии отсутствовали, что, вероятно, связано с дистантностью подобной коммуникации (общение в интернетпространстве).

3. Степень социальной приемлемости коммуникативной ситуации. Как показали результаты эксперимента, в ответах мужчин фактически отсутствуют агрессивные сценарии коммуникативного поведения. В отличие от девушек, входящих в эту же возрастную группу, молодые люди расценивают предъявленные им экспериментальные ситуации как социально приемлемые и готовы идти на контакт с другими участниками заданных коммуникативных ситуаций, не отвечая на раздражитель агрессией. Агрессивные сценарии наблюдались только в единичных случаях: Я отвечу агрессией, так как это было не по моей вине; Взгляну с презрением и промолчу (экспериментальная ситуация № 2); Осуждающе посмотрю на встревающего в разговор и прекрашу данный разговор (экспериментальная ситуация № 3). Как представляется, агрессивный сценарий прогнозируемого коммуникативного поведения отражает желание коммуниканта сохранить целостность своей среды и вытеснить раздражитель из своего личного пространства без совершения каких-либо адаптивных действий. Судя по результатам эксперимента, подобная поведенческая стратегия в большей степени свойственна молодым женщинам, нежели мужчинам. 
Сравн ительный анализ ответов мужчин и женщин в возрасте от 17 до 24 лет выявил следующие особенности этих экспериментальных групп.

При предъявлении экспериментальной ситуации № 1 мужчины предлагают ответы, содержащие меньше речевых / неречевых действий, чем женщины: они рассматривают данную ситуацию как стереотипную и перечисляют только базовые составляющие коммуникативного поведения (только основные речевые / неречевые действия). Так, в экспериментальной группе № 1 одно ответное речевое / неречевое действие содержится в $38 \%$ ответов, два ответных речевых / неречевых действия - в $49 \%$ случаев, три ответных речевых / неречевых действия - в $12 \%$ ответов, четыре ответных речевых / неречевых действия - в 1\% случаев, а в экспериментальной группе № 2 одно ответное речевое / неречевое действие содержится в 49,2 \% случаев, два ответных речевых / неречевых действия - в $32,2 \%$ ответов, три ответных речевых / неречевых действия - в 15,2 \% ответов, четыре ответных речевых / неречевых действия - в 3,4 \% случаев. Такое распределение ответов демонстрирует, что молодые мужчины предлагают ответы, содержащие меньше ответных действий (большинство ответов содержит всего одно ответное действие), чем женщины в возрасте от 17 до 24 лет. Однако при этом участники экспериментальной группы № 2 предлагают сравнительно много развернутых сценариев коммуникативного поведения. Это, в частности, демонстрирует, что молодые мужчины воспринимают такую ситуацию как норму социального поведения, требующую совершения достаточного количества ответных речевых / неречевых действий. Ответы молодых женщин также содержат сравнительно много развернутых сценариев, тем не менее количество таких сценариев статистически менее значимо, чем в случае с мужчинами.

При предъявлении экспериментальной ситуации № 2 молодые мужчины прогнозируют шаблонные последовательности ответных речевых / неречевых действий, содержащие преимущественно одно или два действия. В целом количество ответных действий, включенных в заданную коммуникативную ситуацию, у них меньше, чем у женщин из этой возрастной группы (ср.: одно речевое / неречевое действие - $76,3 \%$ ответов мужчин в возрасте до 24 лет vs. 69 \% ответов женщин в возрасте до 24 лет; два речевых / неречевых действия - 20,3 \% ответов мужчин vs. $29 \%$ ответов женщин. При этом следует отметить большое количество отказов от совершения ответного речевого действия в ответах молодых мужчин (ср.: Взгляну с презрением и промолчу; Извиниться. Если касание незначительное - проигнорировать; Буду стоять дальше; Если замечание вежливо, извиниться, если грубое - оставить без внимания; Отойду в сторону).

Как и в экспериментальной группе женщин, ответы молодых мужчин распределяются в две полярные группы: «вежливые» и «грубые»: Вежливо извинюсь; Извиниться перед человеком, объяснить ситуацию, что вы не виноваты в этом; Взгляну с презрением и промолчу; Буду стоять дальше; Я отвечу агрессией, так как это было не по моей вине и др. Однако в целом женщины в большей степени склонны агрессивно реагировать на подобный раздражитель.

При предъявлении экспериментальной ситуации № 3 молодые мужчины склонны прогнозировать единичные ответные речевые / неречевые действия (одно ответное речевое действие - 72,9\% в группе мужчин vs. $58 \%$ в группе женщин; два ответных речевых / неречевых действия - 20,3 \% в группе молодых мужчин vs. 36 \% в группе женщин; три ответных речевых / неречевых действия $3,4 \%$ vs. $4 \%$ соответственно). Простая коммуникативная ситуация, заложенная в данном экспериментальном задании, вероятно, по мнению молодых людей, не требует совершения большого количества ответных действий для восстановления равновесия со средой. Женщинам из этой возрастной группы свойственно желание оправдаться, объяснить свои действия: Я не очень люблю, когда незнакомые люди вмешиваются в разговор. Из вежливости, я отвечу на его комментарий, но не буду задавать ему вопросов, которые могли бы втянуть его в дальнейтее обсуждение какого-либо вопроса со мной; Удивлюсь его поведению, $и$, если он / она выглядит странно, отойду в сторону, од- 
нако, если его слова на данную тематику "очень в тему», отвечу на его / ее слова; Сначала оценю внешний вид человека и манеру его общения и возраст, если человек будет адекватным и вежливым, то, возможно, продолжу беседу, если же нетвежливо попрошу не вмешиваться в разговор и др.

В этой экспериментальной ситуации молодые мужчины предлагают меньше агрессивных сценариев, чем молодые женщины: $\mathrm{He}$ лезьте в наш разговор. Более того, в их ответах, полученных при предъявлении этой экспериментальной ситуации, часто маркирована вежливость: Вежливо покажу человеку, что он является лишним в разговоре; Отойти, в вежсливой форме показать человеку, что он лезет не в свое дело; Постараюсь понять, знаю ли я этого человека. Если нет, то жестко, но в рамках приличия попрошу его не встревать в разговор и др. Следовательно, мужчины в возрасте от 17 до 24 лет воспринимают заданную коммуникативную ситуацию как социально приемлемую и не возражают против «вторжения» в личный разговор третьего коммуниканта. Они открыты для социального взаимодействия, в то время как девушки в том же возрасте в меньшей степени готовы поддержать диалог с незнакомцем в социально детерминированной ситуации общения.

Экспериментальную ситуацию № 4 и мужчины, и женщины из исследуемой возрастной группы воспринимают как простую, поэтому последовательность прогнозируемых ответных речевых / неречевых действий в ответах испытуемых включает не более одного / двух действий (мужчины: одно ответное действие - 72,9\%; два ответных действия - $11,9 \%$, три ответных действия $5,1 \%$, отказы - 10,2 \%; женщины: одно ответное действие - $79 \%$; два ответных действия $12 \%$, отказы - $9 \%$ ).

Значительное количество отказов от совершения ответного речевого / неречевого действия, полученных при предъявлении именно этой экспериментальной ситуации, связано, как отмечалось выше, с возможностями, открываемыми особой коммуникационной платформой - Интернетом: коммуникант может регулировать состав и иерархию средо- вых факторов и исключать те раздражители, которые препятствуют сохранению равновесия между живой системой (коммуникантом) и его средой. Иными словами, коммуникант не расценивает раздражитель в предъявленной экспериментальной ситуации как релевантный для совершения ответного речевого / неречевого действия. Отсюда и большое число ответов, содержащих отказ от совершения ответного действия, в обеих экспериментальных группах, а в тех случаях, когда сценарий ответного коммуникативного поведения моделируется, входящие в него действия являются простыми: Ответить; Пошутить в ответ; Если критика адекватна - приму к сведению, иначе - проигнорирую; Отиучусь; Поблагодарю за критику (за честность); Отвечу с шуткой, сарказмом и др.

На следующем этапе анализа были изучены ответы испытуемых из экспериментальной группы I, содержащие нелинейные сценарии.

Нелинейные сценарии, которые предлагают участники эксперимента, отражают зависимость выбора адаптационных механизмов от актуального состояния коммуниканта (живой системы). Так, если испытуемый указывает, что его коммуникативное поведение в той или иной экспериментальной ситуации зависит от ряда обстоятельств (настроения, характера взаимодействия, типа раздражителя и др.), он стремится проанализировать собственное состояние на момент вступления в коммуникацию. Такие нелинейные сценарии являются особенно информативными, поскольку они маркируют степень внутригрупповой неоднородности. В каждой экспериментальной группе было подсчитано количество нелинейных сценариев, а результаты статистической обработки были представлены в виде таблиц (см. табл. 9, 10).

Как представляется, нелинейный сценарий коммуникативного взаимодействия выстраивается испытуемым на основе предшествующего коммуникативного опыта, поскольку коммуникант моделирует уже известный ему сценарий коммуникативного поведения в знакомой ему ситуации общения. У участников эксперимента таких шаблонных сценариев сравнительно немного. Ср.: участники женского пола выстраивают нелинейные сценарии в 
К.С. Карданова-Бирюкова. Особенности коммуникативного поведения носителей русского языка

Таблица 9

Тип коммуникативного сценария, выстраиваемый коммуникантом

(женщины, 17 лет - 24 года)

\begin{tabular}{|c|c|c|}
\hline $\begin{array}{c}\text { Номер эксперимен- } \\
\text { тальной ситуации }\end{array}$ & $\begin{array}{c}\text { Тип коммуникативного } \\
\text { сценария }\end{array}$ & $\begin{array}{c}\text { Количество ответов } \\
\text { испытуемых }\end{array}$ \\
\hline \multirow{2}{*}{1} & Линейный сценарий & $68 / 85(80 \%)$ \\
\cline { 2 - 3 } & Нелинейный сценарий & $17 / 85(20 \%)$ \\
\hline \multirow{2}{*}{2} & Линейный сценарий & $75 / 85(88 \%)$ \\
\cline { 2 - 3 } & Нелинейный сценарий & $10 / 85(12 \%)$ \\
\hline \multirow{2}{*}{3} & Линейный сценарий & $58 / 85(68 \%)$ \\
\cline { 2 - 3 } & Нелинейный сценарий & $27 / 85(32 \%)$ \\
\hline \multirow{2}{*}{4} & Линейный сценарий & $56 / 85(66 \%)$ \\
\cline { 2 - 3 } & Нелинейный сценарий & $29 / 85(34 \%)$ \\
\hline
\end{tabular}

Таблица 10

\section{Тип коммуникативного сценария, выстраиваемый коммуникантом} (мужчины, 17 лет - 24 года)

\begin{tabular}{|c|c|c|}
\hline $\begin{array}{c}\text { Номер эксперимен- } \\
\text { тальной ситуации }\end{array}$ & $\begin{array}{c}\text { Тип коммуникативного } \\
\text { сценария }\end{array}$ & $\begin{array}{c}\text { Количество ответов } \\
\text { испытуемых }\end{array}$ \\
\hline \multirow{2}{*}{1} & Линейный сценарий & $52 / 59(88,1 \%)$ \\
\cline { 2 - 3 } & Нелинейный сценарий & $7 / 59(11,9 \%)$ \\
\hline \multirow{2}{*}{2} & Линейный сценарий & $44 / 59(74,6 \%)$ \\
\cline { 2 - 3 } & Нелинейный сценарий & $15 / 59(25,4 \%)$ \\
\hline \multirow{2}{*}{3} & Линейный сценарий & $31 / 59(52,5 \%)$ \\
\cline { 2 - 3 } & Нелинейный сценарий & $28 / 59(47,5 \%)$ \\
\hline \multirow{2}{*}{4} & Линейный сценарий & $37 / 59(62,7 \%)$ \\
\cline { 2 - 3 } & Нелинейный сценарий & $22 / 59(37,3 \%)$ \\
\hline
\end{tabular}

$20 \%$ случаев (экспериментальная ситуация № 1), $12 \%$ случаев (экспериментальная ситуация № 2), 32 \% случаев (экспериментальная ситуация № 3), 34 \% случаев (экспериментальная ситуация № 4).

Линейный же сценарий, напротив, демонстрирует то, что испытуемый ориентируется на стереотипную коммуникативную ситуацию. Он исходит прежде всего из известных ему стереотипных ситуаций, с которыми он вовсе необязательно сталкивался в личном опыте. Так, отвечая на задание, относящееся к экспериментальной ситуации № 2, молодые женщины редко предлагали нелинейные сценарии коммуникативного поведения (в $12 \%$ ответов). Это, вероятно, связано с тем, что в этой экспериментальной ситуации отражена крайне типичная ситуация социального взаимодействия, предполагающая шаблонные ответные речевые / неречевые действия: Извинюсь; Попрошу прощения; Закачу глаза; Проигнорирую или извинюсь (зависит от ситуации); Нахамлю; Промолчу и др.

Сопоставительный анализ ответов мужчин и женщин из экспериментальной выборки показал, что молодые мужчины предлагают значительно больше нелинейных сценариев, чем молодые женщины тогда, когда им предъявляется экспериментальная ситуация № $2(25,4 \%$ vs. $12 \%)$. При этом выбор сценария коммуникативного поведения определяется рядом факторов: реакция человека, которого Вы задели (Извиниться за это и если человек жаждет объяснений, то попьтаться рассказать ему, что это было случайностью; Может попрошу прощения (зависит от реакиии того человека)); характер касания (Извиниться. Если касание незначительное - проигнорировать); характер замечания (Если замечание вежливо, извиниться, если грубое - оставить без внимания). В ряде случаев выбор поведенческого сценария не мотивируется: Либо не обратить внимание, либо ответить на замечание замечанием; Извинюсь или проигнорирую замечание; Попрошу прощения или промолчу.

Женщины в возрасте от 17 до 24 лет предлагают довольно много развернутых ответов, описывающих последовательность ре- 
чевых / неречевых действий: Постараюсь уйти от нежелательного собеседника, стараясь не обидеть человека и сменить тему беседы (экспериментальная ситуация № 3); Обратить внимание этого человека на то, как много людей в вагоне, и сказать, что я не обязана извиняться (экспериментальная ситуация № 2). Вероятно, это демонстрирует то, что испытуемые из этой экспериментальной группы выстраивают некий сценарий поведения в рамках заданной коммуникативной ситуации без опоры на шаблонные ответные действия из своего предшествующего коммуникативного опыта. При этом в ряде случаев описываются не конкретные речевые / неречевые действия, а эмоциональные реакции на них: Извинюсь и буду ульбаться (экспериментальная ситуация № 2); Извинюсь, конечно же, и постараюсь стать как можно меньше, не причиняя дискомфорт окружаюшим (экспериментальная ситуация № 2); Извинюсь и буду долго переживать по этому поводу (экспериментальная ситуация № 2). Такие ответы, вероятно, отражают желание испытуемых из этой экспериментальной группы выстроить более широкий контекст собственного речевого / неречевого поведения (при этом испытуемые отступают от экспериментального задания, расширяя его рамки).

Анализ всей совокупности экспериментальных анкет женщин показал, что их ответы часто бывают полярными. Так, некоторые из них входят в полярные группы: «вежливые»: Извинюсь и скажу, что сделала это не специально (экспериментальная ситуация № 2); Попрошу прощения и сделаю невинное выражение лица (как у котика из «Шрека») (экспериментальная ситуация № 2); Поддержу тему (экспериментальная ситуация № 3) и др. и «грубые»: Закачу глаза (экспериментальная ситуация № 3); Попрошу, чтобы человек отстал (экспериментальная ситуация № 3); Нахамлю (экспериментальная ситуация № 3) и др.

Некоторые ответы можно распределить на шкале «развернутый нелинейный сценарий - минимум действий (отказ от ответных действий)». Так, в первую группу входят ответы, построенные по модели если... то..., например: Если критика по существу, поблагодарю человека за то, что указал на что- то важное, если нет - удалю комментарий (экспериментальная ситуация № 4); Если это не очень личная тема, проявлю интерес к этому человеку; если тема личная, переключусь на другую, чтобы человек понял, что я не желаю обсуждать это с ним (экспериментальная ситуация № 3). Во вторую группу были включены ответы, содержащие одно ответное речевое / неречевое действие или предполагающие отказ от совершения ответного речевого действия, например: Игнор (экспериментальная ситуация № 4); Извинюсь (экспериментальная ситуация № 2); Промолчу (экспериментальная ситуация № 2).

Некоторые ответы испытуемых из экспериментальной группы I вошли в кластер «оценка ситуации как социально приемлемой», например: Продолжу разговор втроем, часто сама комментирую и вступаю в разговор третьих лии (экспериментальная ситуация № 3). Альтернативу этому кластеру составили ответы, вошедшие в кластер «оценка ситуации как социально неприемлемой», например: Сделаю замечание о том, что это некультурно; попрошу знакомого / ую отойти в другое место / в сторону (экспериментальная ситуация № 3).

У частники эксперимента мужского пола в возрасте от 17 до 24 лет предлагают преимущественно неразвернутые ответы, отражающие минимум ответных речевых / неречевых действий: Извинюсь (экспериментальная ситуация № 2); Начнем общаться вместе с ним (экспериментальная ситуация № 3); Ответить (экспериментальная ситуация № 4); Удалю комментарий (экспериментальная ситуация № 4).

При этом ответы молодых мужчин демонстрируют в целом положительное отношение участников этой группы к предъявленным экспериментальным ситуациям: они открыты для коммуникативного взаимодействия, не реагируют на обращенное к ним речевое действие негативно, не конфликтны. Ср.: Ответить так, чтобы не развивать конфликт (экспериментальная ситуация № 2); Ничего не имею против, пусть включается в разговор (экспериментальная ситуация № 3); Обcудить, спросить, что не так с фотографией, чтобы стать лучше (экспериментальная ситуация № 4). Это, несомненно, свиде- 
тельствует об их открытости для социального взаимодействия, о готовности участвовать в коммуникации.

\section{Выводы}

Проведенный анализ ответов испытуемых, полученных в ходе эксперимента, позволяет говорить о том, что наиболее выраженные различия наблюдаются на стыке экспериментальных групп (следует отметить, что в эксперименте также контролировались параметры «возраст» и «социальный статус», которые не были рассмотрены в данной статье). Однако внутригрупповая однородность также является сравнительно невысокой, что позволяет говорить о том, что коммуникация определяется индивидуальными характеристиками живой системы (коммуниканта). Как показали результаты эксперимента, чем более многочисленна группа, тем более выражены различия (больше испытуемых было в группе женщин в возрасте от 17 до 24 лет, и именно в ней наблюдаются самые выраженные расхождения).

Дополнительным подтверждением того, что характер взаимодействия часто определяют индивидуальные особенности коммуниканта, которые в теории аутопоэза называются актуальными состояниями живой системы, выступает то, что в ответах испытуемые часто указывают на субъективные факторы, которые детерминируют характер ответного речевого / неречевого действия (Ср. если не в настроении...).

Эти наблюдения подтверждают выдвинутую на этапе планирования эксперимента гипотезу, согласно которой коммуникант иден- тифицирует сочиальный дисбаланс исходя из собственного актуального состояния, которым определяется алгоритм коммуникации, и позволяют говорить о значимости выявления индивидуальных характеристик коммуникантов прежде, чем приступить к анализу их коммуникативной деятельности.

\section{СПИСОК ЛИТЕРАТУРЫ}

Матурана У., Варела Ф., 2001. Древо познания. М. : Прогресс-традиция. 224 с.

Шеннон К., 1963. Работы по теории информации и кибернетике. М. : Изд-во иностр. лит. 830 с.

Maturana H. R., 1978. Biology of language: the epistemology of reality // Psychology and Biology of Language and Thought: Essays in Honor of Eric Lenneberg. N. Y. : Academic Press. P. 27-63.

Maturana H. R., Varela F., 1980. Autopoiesis and Cognition: The Realization of the Living // Boston Studies in the Philosophy of Science. Dordecht : D. Reidel Publishing Co. Vol. 42.143 p.

\section{REFERENCES}

Maturana H.R., Varela F., 2001. The tree of knowledge. Moscow, Progress-traditsiya Publ. 224 p.

Shennon K., 1963. Papers on information theory and cybernetics. Moscow, Izd-vo inostrannoy literatury. $830 \mathrm{p}$.

Maturana H.R., 1978. Biology of language: the epistemology of reality. Psychology and Biology of Language and Thought: Essays in Honor of Eric Lenneberg. New York, Academic Press, pp. 27-63.

Maturana H.R., Varela F., 1980. Autopoiesis and Cognition: The Realization of the Living. Boston Studies in the Philosophy of Science. Dordecht, D. Reidel Publishing Co., vol. 42.143 p.

\section{Information about the Author}

Kseniya S. Kardanova-Biryukova, Candidate of Sciences (Philology), Associate Professor, Department of Linguistics and Translation Studies, Moscow City University, Maly Kazenny pereulok, 5Б, 105064 Moscow, Russia, kardanova81@yandex.ru, https://orcid.org/0000-0002-6773-1129

\section{Информация об авторе}

Ксения Суфьяновна Карданова-Бирюкова, кандидат филологических наук, доцент кафедры языкознания и переводоведения, Московский городской педагогический университет, Малый Казенный пер., 5Б, 105064 г. Москва, Россия, kardanova81@yandex.ru, https://orcid.org/0000-0002-6773-1129 